\title{
Gastrointestinal symptoms in pregnancy among antenatal clinic attendees in Abubakar Tafawa Balewa University Teaching Hospital Bauchi, Northeast Nigeria
}

\author{
Muhammad Baffah Aminu'*, Mohammed Alkali², Bala M. Audu', Toyin Abdulrazak ${ }^{3}$
}

\author{
${ }^{1}$ Department of Obstetrics and Gynecology, ATBUTH, Bauchi, Nigeria, India \\ ${ }^{2}$ Department of Medicine, ATBUTH, Bauchi, Nigeria \\ ${ }^{3}$ Department of Chemical Pathology, ATBUTH, Bauchi, Nigeria
}

Received: 23 November 2019

Revised: 18 January 2020

Accepted: 24 January 2020

\section{*Correspondence:}

Dr. Muhammad Baffah Aminu,

E-mail: aminubaffahmuhammad@gmail.com

Copyright: () the author(s), publisher and licensee Medip Academy. This is an open-access article distributed under the terms of the Creative Commons Attribution Non-Commercial License, which permits unrestricted non-commercial use, distribution, and reproduction in any medium, provided the original work is properly cited.

\begin{abstract}
Background: Pregnant women are at increasing risk of GI symptoms such as nausea, vomiting and heartburns, most of these symptoms are as a result of the hormonal and physical changes associated with pregnancy. This study aimed to determine prevalence of gastrointestinal symptoms (GI) among pregnant women attending booking clinic at a Northeastern Nigerian Teaching Hospital.

Methods: The study was a cross-sectional, questionnaire-based survey of four hundred and fifty-two pregnant women booking for antenatal care. Their sociodemographic variables as well as the presence or absence of gastrointestinal symptoms in index pregnancy were obtained at by the use of researcher-administered questionnaire. Data were analyzed and presented as frequencies and percentages. A 5\% significance level ( $\mathrm{p}<0.05)$ to test associations.

Results: Two fifty-five women had heart burns (56.4\%) while $235(52.0 \%)$ had nausea in pregnancy, these were observed to be the most prevalent GI symptoms among the women. Diarrhea and hemorrhoids were the uncommon GI symptoms in the study population constituting 406 (89.5\%), and 360 (79.6\%) respectively. Easy fullness was noted in $39.8 \%$ of the women while vomiting was in $41.8 \%$ and constipation in $29 \%$ of the respondents. A significant association was observed ( $\mathrm{p}$ value $<0.05$ ) between parity and development of anorexia and hemorrhoids in pregnancy ( $\mathrm{p}$ values of 0.049 and 0.051 respectively) but not for the other symptoms.

Conclusions: GI symptoms are common in pregnancy, the most prevalent symptoms are that of heart burns and nausea, while diarrhea is relatively uncommon.
\end{abstract}

Keywords: Antenatal, Gastrointestinal symptoms, Pregnant women

\section{INTRODUCTION}

A special period in the life of women where both internal and external changes occur is during pregnancy. ${ }^{1}$ Gastro intestinal symptoms are some of the earliest changes that herald the existence of pregnancy in a woman, they occur largely due to the effects of circulating progesterone and B-HCG in the system, they could be exaggerated with increasing levels of those hormones in conditions such as in multiple pregnancy and molar gestation. ${ }^{2,3}$ Though regarded as physiological to the pregnant women but could indeed be pathological when they occur in nonpregnant women, or when exaggerated with attendant adverse consequences. The circulating progesterone level during pregnancy causes the relaxation of the smooth muscles of the gut resulting in significant delayed time of 
digestion and emptying with resultant constipation. Some of the GI symptoms observed in pregnancy include nausea, vomiting, anorexia, borborygmi and diarrhea. ${ }^{4}$

Varying degrees of these symptoms may or may not affect the outcome of the pregnancy, sometimes with adverse prognosis for both mother and baby. ${ }^{5}$ Some of the symptoms are mild requiring just reassurance but occasionally, they may be severe and thus requiring medical and occasionally surgical intervention. ${ }^{5}$

Studies across the world have indicated the prevalence of these symptoms ranging from 17 to $80 \% .^{6-8}$ Higher prevalence have also been reported with advancing gestational age. Increasing number of women are presenting with gastro intestinal symptoms in pregnancy. This study is therefore aimed at determining the prevalence of GI symptoms among women attending booking clinic at ATB University Teaching Hospital Bauchi, Nigeria.

\section{METHODS}

The study was carried out at Abubakar Tafawa Balewa University Teaching Hospital, Bauchi, Nigeria. All consecutive pregnant women attending the booking clinic of the hospital constituted the study population. The booking clinic was a twice weekly clinic on Tuesdays and Thursdays for a period of six months (February to August 2019). A total of four hundred and fifty-two (452) booked respondents that gave their verbal informed consent had the questionnaire administered by the researcher and trained assistants.

\section{Inclusion criteria}

- Pregnant women within the reproductive age group

- All pregnant women that came for booking who gave verbal consent for the study

- All pregnant women with no Known GIT condition before pregnancy.

\section{Exclusion criteria}

- All pregnant women with prior history of peptic ulcer disease and or constipation pre dating pregnancy

- Pregnant women with or who were on follow up for a known gastrointestinal disease predating pregnancy

- Women that refused to give consent for the study.

A proforma was used for the study which assessed sociodemographic variables of the respondents and presence or absence of GI symptoms.

\section{Statistical analysis}

Data obtained was inputted into and analyzed using SPSS version 21.0 and results presented in table of frequency and percentages with $\mathrm{p}$ values of 0.05 as significant.
Ethical approval was obtained from the Health research and Ethical committee of the ATB University Teaching Hospital, Bauchi.

\section{RESULTS}

A total of four hundred and fifty-two women participated in the survey. Their age ranged between 11 and 45 years with the mean age of $28.4 \pm 4$ years. The majority of the respondents $68.8 \%$ were multigravidas, only $11.5 \%$ of them were grand multiparous women. Four hundred and forty $(97.4 \%)$ were carrying singleton fetuses and ten $(2.2 \%)$ had twin gestation.

Two $(0.4 \%)$ had molar pregnancy that was detected at the time of booking (Table 1).

Table 1: Age, parity, gestational and number of fetuses $(n=452)$.

\begin{tabular}{|lll|}
\hline Factors & \multicolumn{2}{l|}{ Frequency } \\
\hline Age-group & \multicolumn{1}{l|}{} \\
\hline $11-15$ & 1 & 0.22 \\
\hline $16-20$ & 35 & 7.74 \\
\hline $21-25$ & 142 & 31.42 \\
\hline $26-30$ & 131 & 28.98 \\
\hline $31-35$ & 96 & 21.24 \\
\hline $36-40$ & 43 & 9.51 \\
\hline $41-45$ & 4 & 0.88 \\
\hline Parity & & \\
\hline Primigravida & 89 & 19.70 \\
\hline Multigravida (2-4) & 311 & 68.80 \\
\hline Grand multipara (> 5) & 52 & 11.50 \\
\hline Gestational age (Weeks) & & \\
\hline$<13$ & 30 & 6.64 \\
\hline $14-27$ & 314 & 69.47 \\
\hline$>28$ & 108 & 23.89 \\
\hline Number of fetuses & & \\
\hline Single & 440 & 97.35 \\
\hline Twins & 10 & 2.21 \\
\hline Molar & 2 & 0.44 \\
\hline
\end{tabular}

Two hundred and fifty-five women had heart burns $(56.4 \%)$ while $235(52.0 \%)$ had nausea in pregnancy, these were observed to be the most prevalent GI symptoms in the study (Table 2).

Diarrhea and hemorrhoids were the uncommon GI symptoms in the study population constituting 406 $(89.5 \%)$ and $360(79.6 \%)$ respectively.

Easy fullness was noted in $39.8 \%$ of the women while vomiting was in $41.8 \%$ and constipation in $29 \%$ of the respondents. One hundred and thirty-eight women $(30.5 \%)$ gave a history of borborygmi and $20.4 \%$ had hemorrhoids. 
A significant association was observed ( $p$ value $<0.05$ ) between parity and development of anorexia and hemorrhoids in pregnancy ( $p$ values of 0.049 and 0.051 respectively) but not for the other symptoms (Table 2). Most of the multigravidas in the study had some of the GI symptoms that were not statistically significant compared to the symptoms of anorexia and hemorrhoids where a significant association exist between multiparity and theire occurrence with X2 of $6.044 \mathrm{p}$ value $(0.049)$ and $\mathrm{X}^{2}$ of 5.967, $\mathrm{p}$ value $(0.051)$ (Table 3 ).

Table 2: Description of gastrointestinal symptoms and their frequency.

\begin{tabular}{|llll|}
\hline \multirow{2}{*}{ Symptoms } & & Frequency & $\%$ \\
\hline \multirow{2}{*}{ Easy fullness } & Yes & 255 & 56.40 \\
\cline { 2 - 3 } & No & 197 & 43.60 \\
\hline \multirow{2}{*}{ Nausea } & Yes & 180 & 39.80 \\
\cline { 2 - 4 } & No & 272 & 60.20 \\
\hline \multirow{2}{*}{ Dyspepsia } & Yes & 235 & 52.00 \\
\cline { 2 - 4 } & No & 217 & 48.00 \\
\hline \multirow{2}{*}{ Vomiting } & Yes & 139 & 30.80 \\
\hline \multirow{2}{*}{ Diarrhea } & No & 313 & 69.20 \\
\hline \multirow{2}{*}{ Constipation } & Yes & 189 & 41.80 \\
\cline { 2 - 4 } & No & 263 & 58.20 \\
\hline \multirow{2}{*}{ Anorexia } & Yes & 46 & 10.20 \\
\hline \multirow{2}{*}{ Borborygmi } & No & 406 & 89.80 \\
\hline \multirow{2}{*}{ Hemorrhoid } & Yes & 131 & 29.00 \\
\cline { 2 - 4 } & No & 321 & 71.00 \\
\hline & Yes & 135 & 29.90 \\
\cline { 2 - 4 } & No & 317 & 70.10 \\
\hline & Yes & 138 & 30.50 \\
\cline { 2 - 4 } & No & 314 & 69.50 \\
\hline & Yes & 92 & 20.40 \\
\hline
\end{tabular}

Table 3: Association between parity and symptom.

\begin{tabular}{|c|c|c|c|c|c|c|}
\hline Parity & Response & Primigravida & Multigravida & Grand multipara & Total & $x^{2}(p$ value $)$ \\
\hline \multirow{2}{*}{ Hearth burns } & Yes & 48 & 177 & 30 & 255 & \multirow{2}{*}{$0.289(0.866)$} \\
\hline & No & 41 & 134 & 22 & 197 & \\
\hline \multirow{2}{*}{ Easy fullness } & Yes & 38 & 118 & 24 & 180 & \multirow[b]{2}{*}{$1.635(0.441)$} \\
\hline & No & 51 & 193 & 28 & 272 & \\
\hline \multirow{2}{*}{ Nausea } & Yes & 42 & 163 & 30 & 235 & \multirow{2}{*}{$1.521(0.467)$} \\
\hline & No & 47 & 148 & 22 & 217 & \\
\hline \multirow{2}{*}{ Dyspepsia } & Yes & 31 & 93 & 15 & 139 & \multirow{2}{*}{$0.889(0.641)$} \\
\hline & No & 58 & 218 & 37 & 313 & \\
\hline \multirow{2}{*}{ Vomiting } & Yes & 35 & 129 & 25 & 189 & \multirow{2}{*}{$1.079(0.583)$} \\
\hline & No & 54 & 182 & 27 & 263 & \\
\hline \multirow{2}{*}{ Diarrhea } & Yes & 11 & 31 & 4 & 46 & \multirow{2}{*}{$0.83(0.66)$} \\
\hline & No & 78 & 280 & 48 & 406 & \\
\hline \multirow{2}{*}{ Constipation } & Yes & 24 & 93 & 14 & 131 & \multirow{2}{*}{$0.411(0.813)$} \\
\hline & No & 65 & 218 & 38 & 321 & \\
\hline \multirow{2}{*}{ Anorexia } & Yes & 18 & 97 & 20 & 135 & \multirow{2}{*}{$6.044(0.049)$} \\
\hline & No & 71 & 214 & 32 & 317 & \\
\hline \multirow{2}{*}{ Borborygmi } & Yes & 31 & 90 & 17 & 138 & \multirow{2}{*}{$1.262(0.532)$} \\
\hline & No & 58 & 221 & 35 & 314 & \\
\hline \multirow{2}{*}{ Hemorrhoid } & Yes & 11 & 66 & 15 & 92 & \multirow{2}{*}{$5.967(0.051)$} \\
\hline & No & 78 & 245 & 37 & 360 & \\
\hline
\end{tabular}




\section{DISCUSSION}

This study was aimed at assessing GI symptoms among pregnant women attending booking clinic of a tertiary health facility in Northeastern Nigeria. About $59.4 \%$ of the sampled population had heartburns, while a little more than half $(52.0 \%)$ had nausea in the index pregnancy. Audu et al in Maiduguri in a similar study more than a decade ago reported about $45 \%$ for heart burns and $39.9 \%$ for nausea among their studied group, showing an increasing prevalence of these symptoms since the study population are in the same region and likely to be similar. ${ }^{9}$

This finding was also supported by a systematic overview by Vazquez $\mathbf{J}$ where heart burns were common GI symptom among pregnant women with prevalence of 17 to $45 \%$ and as much as $70 \%$ in the last trimester of pregnancy. ${ }^{7}$ Heart burns occurs because of the higher level of progesterone and its metabolites resulting in decrease tone and motility of the gut and subsequently decrease the pressure of the lower esophageal sphincter, gastroesophageal reflux and a burning feeling. ${ }^{7}$ This can be managed through life style modifications, drugs and sometimes minimal invasive procedures or even no intervention at all. ${ }^{10-12}$ While for the nausea which begins in the first 28 days and peak at 9 weeks following the last menses, it is usually accompanied by vomiting in half of cases and occur in isolation in additional quarter. ${ }^{14}$ Fluid intake and avoidance of food and smell inducing nausea may be the only adjustment.

A multicenter study involving 2411 women indicated the prevalence of nausea and vomiting in pregnancy of $88 \%$, this was for combined symptoms of nausea and vomiting. ${ }^{15}$ The observed low value for vomiting in pregnancy in our study was the fact that the majority of the study population were in their second half of pregnancy, and the symptoms of nausea and vomiting tends to subside as pregnancy advances, this is as a result of the reduction in the circulating levels of hormones like B-HCG.

Vomiting when it occurs in pregnancy must be adequately evaluated as sometimes self-induced vomiting may be mistaken for vomiting associated with eating disorder. ${ }^{16}$ Even though constipation was significantly low $(29.0 \%)$ in this study, a systematic review indicated that it is another common symptom in pregnant women in Shanghai with a prevalence of $13.0 \%$ among women that were over 35 years, educated and of higher social class, their findings was due to the fact that the majority of the women in that region were postponing child bearing to a later age of 34 and above leading to mood swings and subsequently, constipation. ${ }^{17}$ Another study by Vazquez et al indicated the prevalence of constipation in pregnancy at 11 to $35 \% .{ }^{6}$ Despite the seemingly low figure for constipation in this study, the prevalence is still more than that in the Chinese study, this may be due to the large sample size in their study when compare to this study. Similarly, constipation in pregnancy has been found to be commoner among sedentary women, and women in this north east region hardly engage in exercise during pregnancy and their intake of fruits and vegetable in pregnancy is equally low. All these factors may add up to the smooth muscle relaxing effects of progesterone to cause constipation which is considered as one of the five causes of gastrointestinal distress in pregnant population. ${ }^{18}$

There appeared to be a significant association between parity and occurrence of haemorrhoids from in this study, close to one third of the respondents indicated the symptom from the survey, similar figure had been quoted from another study by Longo et al with raised blood volume and intraabdominal pressure exerted by the growing uterus, as well as the relaxing effects of circulating progesterone as the possible risk factors for the development of haemorrhoids. ${ }^{19}$

Others had alluded to the high vascularity of the perianal vessels, but the symptoms are commoner in the last part of pregnancy and could persist even after delivery with significant life sequelae. ${ }^{20-24}$

\section{CONCLUSION}

GI symptoms like heartburn, nausea and vomiting are common in pregnancy and their prevalence may be on the increase, their occurrence should not be seen as normal. Thus, other pathological causes of these symptoms should be evaluated and appropriately handled. It is therefore, important to determine whether their occurrence is normal or whether it has any adverse impact on pregnancy and future health outcomes.

\section{Funding: No funding sources}

Conflict of interest: None declared

Ethical approval: The study was approved by the Institutional Ethics Committee

\section{REFERENCES}

1. Shi W, Xu X, Zhang Y, Guo S, Wang J, Wang J. Epidemiology and risk factors of functional constipation in pregnant women. PloS One. 2015;10(7):e0133521.

2. Body C, Christie JA. Gastrointestinal diseases in pregnancy: nausea, vomiting, hyperemesis gravidarum, gastroesophageal reflux disease, constipation, and diarrhea. Gastroenterol Clin. 2016;45(2):267-83.

3. Soma-Pillay $\mathrm{P}$, Catherine NP, Tolppanen $\mathrm{H}$, Mebazaa A, Tolppanen H, Mebazaa A. Physiological changes in pregnancy. Cardiovascular $\mathbf{J}$ Africa. 2016;27(2):89.

4. Longo SA, Moore RC, Canzoneri BJ, Robichaux A. Gastrointestinal conditions during pregnancy. Clin Colon Rectal Surge. 2010;23(2):80-9. 
5. Keller J, Frederking D, Layer P. The spectrum and treatment of gastrointestinal disorders during pregnancy. Nat Clin Pract Gastroenterol Hepatol. 2008;5:430-43.

6. Vazquez JC. Constipation, haemorrhoids, and heartburn in pregnancy. BMJ Clin Evid. 2010;2010.

7. Vazquez JC. Heartburn in pregnancy. BMJ Clin Evid. 2015;2015.

8. Gomes CF, Sousa M, Lourenço I, Martins D, Torres J. Gastrointestinal diseases during pregnancy: what does the gastroenterologist need to know?. Ann Gastroenterol. 2018;31(4):385.

9. Audu BM, Mustapha SK. Prevalence of gastrointestinal symptoms in pregnancy. Nigerian J Clin Pract. 2006;9(1):1-6.

10. Roark R, Sydor M, Chatila AT, Umar S, De La Guerra R, Bilal M, Guturu P. Management of gastroesophageal reflux disease. Am Fam Physician. 2003;68(7):1311-9.

11. Kessing BF, Bredenoord AJ, Smout AJ. A pregnant patient with excessive belching. Dis Oesophagus. 2016;29(6):688-9.

12. Phupong $\mathrm{V}$, Hanprasertpong $\mathrm{T}$. Interventions for heartburn in pregnancy. Cochrane Database Syst Rev. 2015:9.

13. Niebyl JR. Nausea and vomiting in pregnancy. New England J Med. 2010;363(16):1544-50.

14. Jarvis S, Nelson-Piercy C. Management of nausea and vomiting in pregnancy. BMJ. 2011;342:d3606.

15. Ellilä $P$, Laitinen L, Nurmi M, Rautava P, Koivisto M, Polo-Kantola P. Nausea and vomiting of pregnancy: a study with pregnancy-unique quantification of emesis questionnaire. Eur J Obstet Gynaecol Reprod Biol. 2018;230:60-7.

16. Chinello A, Dolci V, Galli CM, Faggioli SC, Tugnoli E, Zappa LE. Pregnancy and anorexia nervosa: will, weight and feelings. J Psychol. 2016;3(1):25.
17. Xin HW, Zhu LM, Fang XC, Fei GJ, Yao F, Wang LY, et al. A survey on emotion and sleep status in patients with functional constipation. Chin $\mathbf{J}$ Gastroenterol. 2012;17(2):87-90.

18. Zielinski R, Searing K, Deibel M. Gastrointestinal distress in pregnancy. The J Perinatal Neonatal Nurs. 2015;29(1):23-31.

19. Longo SA, Moore RC, Canzoneri BJ, Robichaux A. Gastrointestinal conditions during pregnancy. Clin Colon Rectal Surg. 2010;23(2):80-9.

20. Buckshee K, Baxla AP. Emerging trends of diosmin treatment in haemorrhoids during pregnancy: a review. Indian Obstet Gynaecol. 2018;8:1.

21. Martínez-Galiano JM, Hernández-Martínez A, Rodríguez-Almagro J, Delgado-Rodríguez $\mathrm{M}$, Gómez-Salgado J. Relationship between parity and the problems that appear in the postpartum period. Scientific Rep. 2019;9(1):1-8.

22. Åhlund S, Rådestad I, Zwedberg S, Edqvist M, Lindgren H. Haemorrhoids: a neglected problem faced by women after birth. Sexual Reproductive Healthcare. 2018;18:30-6.

23. Hollingshead JR, Phillips RK. Haemorrhoids: modern diagnosis and treatment. Postgraduate Med J. 2016;92(1083):4-8.

24. Lamb K, Sanders R. Constipation and haemorrhoids: a midwifery perspective for the childbearing continuum. Br J Midwifery. 2015;23(3):171-7.

Cite this article as: Aminu MB, Alkali M, Audu $\mathrm{BM}$, Abdulrazak T. Gastrointestinal symptoms in pregnancy among antenatal clinic attendees in Abubakar Tafawa Balewa University Teaching Hospital Bauchi, Northeast Nigeria. Int J Reprod Contracept Obstet Gynecol 2020;9:1029-33. 